\title{
Entrevista a Evo Morales Ayma, Presidente del Estado Plurinacional de Bolivia ${ }^{1}$
}

\author{
Interview with Evo Morales Ayma, President \\ of the Plurinational State of Bolivia
}

\author{
Penélope Canónico ${ }^{2}$, Carolina Cabado ${ }^{3}$, \\ Juan Cruz Galeano ${ }^{4}$, Bernardo Vázquez, \\ Guillermo Raúl Moreno y Pablo Octavio Cabral ${ }^{7}$ \\ Universidad Nacional de La Plata - Argentina
}

Revista Derechos en Acción ISSN 2525-1678/ e-ISSN 2525-1686

Año 5/N ${ }^{0} 16$ Invierno 2020 (21 junio a 20 septiembre), 855-863

DOI: https://doi.org/10.24215/25251678e446

\footnotetext{
1 La desgravación de la entrevista fue realizada por Grecia Antonella Tiburcio Montoya, estudiante de la carrera de derecho de la Facultad de Ciencias Jurídicas y Sociales de la Universidad Nacional de La Plata.

2 Periodista, Licenciada en Letras y Abogada. Magister en periodismo, UDESA (en curso).

3 Lic. Comunicación Social, UNLP. Socia fundadora de Chapuzón, Agencia de Comunicación Integral.

4 Estudiante de quinto año de Abogacía, Facultad de Ciencias Jurídicas y Sociales, UNLP.

5 Estudiante de 5 to año de Abogacía. Facultad de Ciencias Jurídicas y Sociales La Plata.

6 Abogado, Especialista en Derecho Constitucional, profesor de Historia Constitucional de la Facultad de Ciencias Jurídicas y Sociales de la UNLP. (ORCID: https://orcid.org/0000-00026334-659X).

7 Abogado, Especialista en Derecho Administrativo y Administración Pública (UNLP), docente de la Facultad de Ciencias Jurídicas y Sociales de la UNLP. Email: pablooctaviocabral@ yahoo.com.ar (ORCID: https://orcid.org/0000-0001-5768-4958).
} 


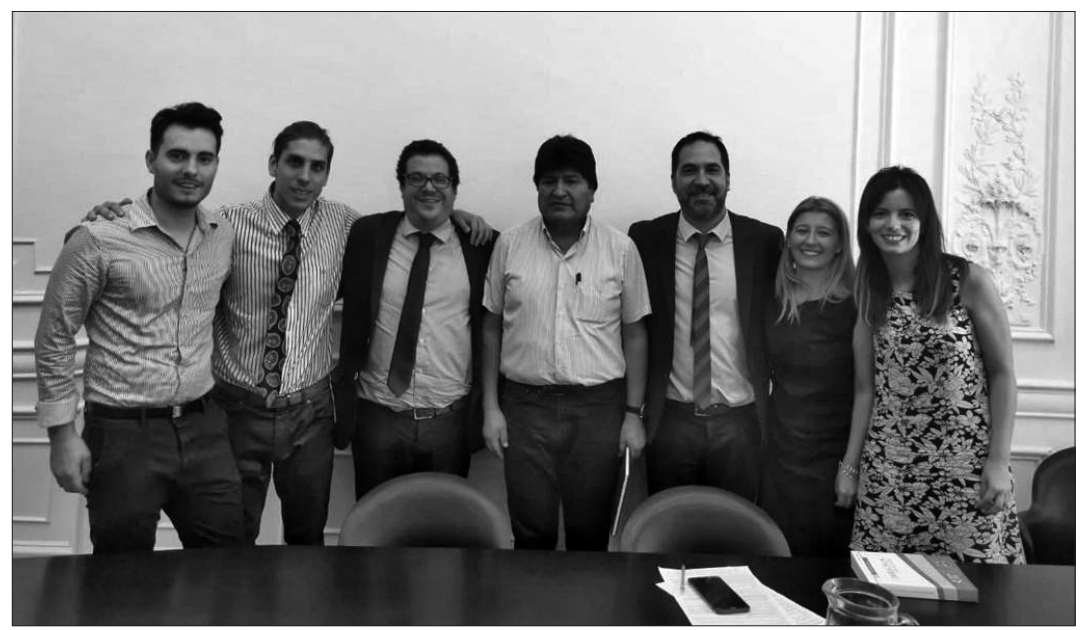

REDEA: Nuestra publicación es una revista jurídica que sale cada 3 meses, en ella tenemos una sección destinada a entrevistas, en donde hemos conversado con distintas personalidades políticas, estadistas, juristas, dirigentes sociales. En primer lugar, queremos preguntarle si nos puede hacer un pequeño recuento de lo que fue su carrera política, su ascenso, sabemos que estuvo viviendo en Argentina... si quiere, también nos puede contar esa situación. Para nosotros va a ser muy gratificante. ¿Cómo fue su ascenso, su paso por sindicalismo, y su paso por nuestro país?

E.M.: Bueno, muchas gracias. Cuando era niño vi a mucha gente que migro acá, comunidades campesinas originarias, milenarias. Mi padre una sola vez me trajo a mí y a mi hermana. Recuerdo que de niño cuando llegaban del campamento unos tractores de una chacra que nos llevaban a la escuela. Yo era aymara y no entendía el castellano; tendría entre 4 y 5 años. Solo entendía cuando la profesora se acercaba y me decía "Evito, Evito", y nos acariciaba el cabello, eso me acuerdo. Siempre me acuerdo que la primera escuela que me vine fue en la zona de Jujuy. Me acuerdo también, cuando acabó la zafra, después del campamento dejamos la escuela. Como yo 
no podía ir a la zafra, mi papá se iba y mi hermana le llevaba comida. Entonces comencé a vender helados, .... y vendía bien. Fue cuando pensé, una parte lo voy a ahorrar para comprarme una pelota, y así una parte de lo que ganaba lo entregaba a mi papá y otra lo enterraba en el suelo, para que él no se enterara. Cuando llegó la hora de retirarnos, delante de mi papá no podía desenterrar la plata...,hasta ahora debe estar allí enterrada en el suelo! Y después ingresé como soldado, debo ser el único presidente que ha ido al cuartel. Allí hay una norma: servicio militar obligatorio. Después ningún presidente ha ido al cuartel. En el altiplano boliviano cuando hay helada o sequía no hay que comer; así es como se vive en el altiplano. Mi padre dijo "vamos a yuga de La Paz, vámonos a Santa Cruz para mejorar la situación". Mi gran deseo era plantar naranja, coca, u otro producto, y con esa ganancia estudiar en la Sierra de Cochabamba; quería ser periodista y en el $88^{\prime}$ me nombran como dirigente de la federación, mi primer cargo en el sindicato fue de Secretario de Deportes; mi primer apodo era "el joven pelotero" ...y ya de delegado de base iba a las negociaciones de los diligentes municipales cuando era gerente del sindicato, no de la federación, y algunos compañeros planteaban transformaciones profundas, y las respuestas del gobierno de la derecha eran "tú estás haciendo política, tú no puedes hacer política", eso me sorprendía. Yo como delegado no debatía, solo escuchaba, y después recordaba que en el altiplano boliviano también nos decían que la política del campesino del altiplano es "palo y pico", pero cuando llegan las elecciones estas votando por ellos.

REDEA: ¿Y cómo se llega del sindicalismo a ocupar la primera magistratura del país?

E.M.: Yo me preguntaba ¿Y por qué en la década del 90 no hubo dirigentes campesinos? ¿Hasta cuándo los de afuera nos van a gobernar? ¿Cuándo nosotros mismos nos vamos a gobernar?... Este movimiento político nace sobre el "indígena". Inclusive, en el Departamento de Santa Cruz, no querían que entre ningún profesional. Hemos empezado a debatir, a avanzar, y en el 99 
dijimos "De una vez". El primer nombre fue ASP, "Asamblea por la Soberanía del Pueblo", y el segundo fue IPSP, "Instrumento Político por la Soberanía del Pueblo". Y la derecha, con instrucciones de la Embajada de Estados Unidos, nunca nos aprobaron. Era campeón de recaudar firmas, cumplir con las formalidades.

REDEA: Después se convirtió en un símbolo de la identidad de Latinoamérica, además usted está atravesando una cuestión bastante compleja donde hay muchos cambios de movimientos sociales y políticos que corresponden a una lógica contra el capitalismo. Tuvo la oportunidad de conocerlo a Eduardo Galeano, un escritor que lo cita muchas veces, y para parafrasear un poco su libro, ¿Usted cree que es momento de cerrar las venas abiertas de América Latina?

E.M.: Hay libros como "La revolución india de Bolivia", "Manifiesto del Partido Indio de Bolivia", "Cien años de invasión de Estados Unidos a Bolivia”, pero recuerdo, cuando en la escuela leí "La Revolución India" de Fausto Reinaga, ese libro me hizo dar cuenta como era la armonía en el mundo, como era la sociedad, ahí me di cuenta de la repartija del Imperio Norteamericano y Europeo en tiempos de la colonia... para reflexionar, para entender la situación social es importante.

REDEA: Que es problema del litio

E.M.: Tema litio... es otro tema; pero yo he sido convencido "este golpe es golpe al litio". Dos cosas no nos han perdonado Estados Unidos. Si ustedes escuchan, durante tantos encuentros... hemos demostrado sin el Fondo Monetario Internacional, sin el Banco Mundial, y por lo tanto sin el sistema capitalista norteamericano que hemos avanzado hacia otro mundo posible, inclusive económicamente, ha bajado la pobreza, la desigualdad, ha aumentado la esperanza de vida... tantos datos. Cuando llegamos al gobierno: PIB: 9 mil millones de dólares. Yo digo "Desde 1825 hasta el 2005 nos dejaron con 9 mil millones de dólares del PIB". Para el ante año pasado, diciembre del 2019, o 18, 40 mil 800 millones de dólares del PIB. ¿Cómo 
podés entender eso? ... ¿En Bolivia que hicimos?... ya vamos a empezar a sustituir la importación, y nos han propuesto la industrialización del litio, este año está previsto inaugurar la primera gran planta de carbonato de litio, con la capacidad de 350 mil toneladas. En el programa de 41 plantas, tenemos 2 plantas más, 3 plantas de carbonato de litio, de hidróxido de litio. Ya tenemos una planta piloto de material de litio. China entró, entró Alemania; dije yo "sin Estados Unidos" ... la brecha con Estados Unidos ¿Cómo es el tema energético en el Siglo 21? ...eso no nos perdonó. Pero ¿Qué hemos propuesto para llegar al gobierno? 3 cosas sencillas: en lo político: la refundación de Bolivia; en lo económico y en lo social: la redistribución de las riquezas. Lo más difícil ha sido la refundación, sufrimos 3 años. Con la nueva constitución dejamos el estado colonial para tener un Estado Plurinacional, todos tienen los mismos derechos, sobre todo los más marginados, en el sector indígena, las mujeres de distintas clases sociales. En lo económico ha sido sencillo porque dependía del decreto: Decreto Supremo de Nacionalización..., y los resultados, por ejemplo, en casi 20 años del gobierno neoliberales, ¿Cuánto fue la renta petrolera? 3 mil millones de dólares ¿Y con nuestra gestión, desde el 2006 al 2018? 38 mil millones de dólares. Hemos diversificado la parte productiva. Y el tema de la redistribución de riquezas, en su proceso que viene de los más humildes, de la gente pobre.

REDEA: Una pregunta vinculada con lo jurídico es, ustedes utilizaron una herramienta jurídica como es la Constitución, el proceso constituyente, tuvieron un proceso histórico largo para sancionarla, con diferentes obstáculos, y lo que le quiero preguntar es, la luz del resultado, que vemos un golpe de la derecha contra un gobierno popular, democrático, constitucional, con logros económicos, con logros culturales, con redistribución, ¿Repensaron la opción institucional o están conformes con la vida democrática institucional? Porque se replicó un poco la historia de Chile con Allende, que fue una revolución a partir de una elección democrática que termina con un golpe de estado. Estamos viendo una historia que se repite: una revolución 
democrática con éxitos económicos pero que termina con un golpe de Estado.

E.M.: Yo creo que va a ser motivo de estudio ver pasa en Bolivia. Generalmente se siente y se hace que las sublevaciones, las rebeliones es contra Estados, Estados sin clases, un Estado impostor, pero es totalmente diferente. A mi, también me ha sorprendido, en nuestro caso hay mucha confianza. Hemos derrotado varios golpes, en 2008 derrotamos un golpe de estado, en 2011 otro golpe de estado, porque mucha gente estuvo militando "Villaroel, Villaroel" cerca de la Plaza Molina. A Villaroel lo colgaron en la década del 40. Dos semanas de paro, la policía marchaba quemando calle cada día. Varios golpes derrotamos. La marcha de los discapacitados financiados por la derecha. Y como somos expertos para derrotar golpes, igualmente nos preguntamos con Álvaro, Vicepresidente, "No, hay que aguantar, una semana, dos semanas, se va a caer. Cuando crece, crece, crece; pero... bien organizados y financiados", eso nos ha sorprendido. No solo nuestro gobierno, también nuestro movimiento social ¿Por qué comento esto? Porque evidentemente con tantos movimientos sociales, con tantos resultados ¿Cómo podría haber un golpe? Yo diría "el imperio no duerme", está pensando cómo, donde y cuando atacar y cuando el imperio muerde, no suelta. Ahora si tenemos un gran desafío. Post elecciones, no teníamos un plan B para enfrentar el golpe, repito "muy confiados". Mientras que en otros países, la sublevación son contra el modelo capitalista, en Chile tantas movilizaciones, Colombia, Ecuador, la democracia que se están recuperando como en Argentina. Nos preguntamos "no estamos en tiempos... en aquellos tiempos, así como con Correa, con Chávez, con Lula, con Kirchner... de eso bajamos; y las obras, legados de esos tiempos han sido sepultados. Pero aquí, pienso en Bolivia porque esto es sublevación de la derecha fascista racistas, esos se oponen. Quiero comentarles, con el tema de campaña estaba en Santa Cruz y el consejo me pide reuniones, distintos sectores sociales vienen movimiento de jóvenes, hijos de clase alta, clase media alta, y yo le dije 
"tienen que hacer lo que hace Salvatierra, nuestra Senadora joven, Adriana Salvatierra, hagan política como Salvatierra". Yo siento que allí está el resentimiento de algunos grupos sociales, y que algunos sectores sociales se han sentido desplazados por gente que históricamente nunca hizo política, y también nuestra misma gente, cerca de 3 millones sacamos de la pobreza, pasando a la clase media, ellos tienen otras expectativas, y el problema es la comunicación permanente o la formación ideológica, cuando ya tiene más plata se olvidan de donde vienen. Repito, va a ser motivo de estudio, pero algo quiero que sepan, en nuestra constitución están los derechos colectivos, y hemos empezado a universalizar muchos derechos. Con el tema de comunicación, cuando llegamos, Entel Movil estaba en apenas 70 Municipios, Bolivia tiene 340 Municipios. Nacionalizamos y llegamos a todos los Municipios: internet, luz, agua, con el programa "Mi Agua". Yo creé un programa llamado "Bolivia Cambio", hicimos escuelas de primer campo, en los barrios, y con mejor equipamiento y tecnología para los laboratorios. Ahí vamos a empezar a universalizar los derechos. La diferencia, también, que tenemos con la derecha es en educación y servicio, para nosotros es derecho; los servicios básicos: agua, luz, telecomunicación; para la derecha es negocio privado. Para nosotros es un servicio del estado, no es privado. Quiero que sepan, de 1825 hasta el 2005 hubo un presidente promedio cada dos años. Yo estaba soldado, en el 78, ese año conocí tres presidentes, en el año 79, otros 3, 4 presidentes. Cinco años antes de que llegara al gobierno, 5 presidentes...

REDEA: Y en esa época, ¿Los golpes también eran producto por los recursos naturales?

E.M.: La lucha de la humanidad, del planeta, es ¿quién controla los recursos naturales? Y no sé si en toda América, ustedes saben que durante la colonia intentaron el exterminio del grupo indígena. Y algunos países como Perú, Ecuador, Guatemala, México, Bolivia; en Bolivia la mayoría seguimos siendo indígenas. Esa es una lucha de clases. Después los gobiernos 
liberales, implementaban una política del saqueo que viene del imperio europeo... vienen las dictaduras militares, cuando empezaron las sublevaciones. Las primeras sublevaciones, para la fundación de las repúblicas; las segundas sublevaciones por los recursos naturales ¿Qué dijimos? De la resistencia a la toma del poder, ¿Hasta cuando?... 500 años de resistencia, ¿otros 500 años de resistencia? Decidimos entonces cómo organizarnos para ir a la toma del poder, y lo íbamos a cumplir. Nosotros nos preguntábamos "¿hasta cuándo desde arriba, los de afuera, nos van a gobernar?”, nosotros tenemos que gobernarnos.

REDEA: ¿Y ya tienen quien va a ser su candidato del MAS? ¿Ya tienen su nombre o se va a presentar usted?

E.M.: Estará el 19 de este mes

REDEA: Una primicia...

E.M.: Yo no lo sé todavía.

REDEA: ¿Y no le temen al fraude?

E.M.: Esa es nuestra gran duda, estamos debatiendo... Yo siento que la embajada debe tener infiltrado en el grupo. Cada vez estamos 5 de la mañana, 6 de la mañana, en reuniones debatiendo sistemas, y ahora protestando, Estados Unidos contra el gobierno de Argentina. Entonces me da miedo, que es el perjuicio, molestia. Argentina, los argentinos van a decir "Bolivia es justamente para hacer campaña". Un momento yo pensé "acabo mi gestión, me dedico a mi vida personal, familiar, voy a hacer mi restaurante en Chapare, pescado tambaqui, vengan a visitar ustedes, voy a comenzar a trabajar en mi chacra..., y ahora como me han hecho golpe..., mientras tenga la vida vamos a hacer política, pero una política con consciencia de servicio.

REDEA: Para ir cerrando, y agradeciéndole además este encuentro Sr. Presidente, ¿Cuál es su mirada hacia el futuro de su patria, de Bolivia, y su futuro personal y político? ¿Qué es lo que espera de acá al futuro? 
E.M.: Esperamos que las elecciones sean libres y transparentes. Acá hay refugiados, perseguidos, hay encarcelados por terrorismo, por sedición; algunas víctimas de las dictaduras militares, viejitos todavía, ¿Qué dicen? "Estamos viviendo peor que la dictadura militar. Si no hay represión hasta el momento, por ahí hay una persecución”. Somos un Estado Plurinacional, tenemos derechos a usar pollera, otros son indígenas, ¿Cómo vamos a entender? si en 13 años hemos demostrado que Bolivia tiene mucho futuro, mucha esperanza; eso quería debatir personalmente, con mucho orgullo, para acabar con el fascismo y el racismo.

REDEA: ¿Cómo cree que lo juzgara la historia muchos años después, la pluma de los historiadores como cree que lo van a recordar?

E.M.: No sé...espero que me recuerden por el esfuerzo, yo no conocía sábado ni domingo, no conozco feriados, no conozco vacaciones. Algunos me preguntaban “¿Cuándo vacaciones?” la mejor satisfacción para mi es la gestión. Entonces, más allá de lo que puedan decir el día de mañana, nuestro gran desafío hoy es recobrar la democracia.

REDEA: Bueno, estamos muy agradecidos. Estamos también contentos de que haya elegido nuestro país para residir en esta situación tan difícil, siéntase como en su casa.

E.M.: Muchas gracias 